\title{
ENSINO DA FOTOGRAFIA NO CAP-UERJ: FORMAÇÃO DO OLHAR E DESENVOLVIMENTO DE COMPETÊNCIAS
}

VALENTIN, Andreas ${ }^{1}$

\begin{abstract}
ResUmo
As práticas contemporâneas da fotografia e da imagem em movimento configuram-se como uma linguagem universal dos tempos atuais e apontam para a necessidade de uma educação do olhar e de uma nova configuração da assim chamada "alfabetização visual". Nesse sentido, o ensino regular da fotografia no ambiente escolar vem conquistando espaços e buscando suas metodologias próprias.

Há muitos anos, o CAp-UERJ se destaca como uma instituição onde práticas artísticas em suas várias manifestações são valorizadas e oferecidas como disciplinas curriculares desde o $1^{\circ}$ ano do Ensino Fundamental. Hoje, o ensino da Fotografia ocorre no 90 ano do Ensino Fundamental e no 10 ano do Ensino Médio. Após uma breve reflexão sobre a natureza da imagem digital e seu distanciamento cada vez maior como registro do real, tratamos aqui do ensino da Fotografia no âmbito do CAp-UERJ e, de forma mais ampla, de alguns de seus desdobramentos na formação humanística dos jovens.
\end{abstract}

PalaVRas-Chave: Artes - Fotografia - Ensino das Artes - Ensino da Fotografia - CAp-UERJ.

\begin{abstract}
Contemporary photography and moving image practices can be considered as a universal language of our times pointing to the need for an education of seeing and a new configuration of the so-called "visual literacy". In this sense, the regular teaching of photography in schools has gained spaces and is seeking for its own methodologies.

For many years, CAp-UERJ stands out as an institution where artistic practices in its various manifestations are valued and offered as curricular subjects beginning in the first grade. Today, photography is taught takes place in the 9th grade and $10^{\text {th }}$ grades. After a brief reflection on the nature of the digital image and its increasing detachment from registering the real world, treated here are the teaching of photography at CAp-UERJ and some of its implications on the humanistic education of youngsters.
\end{abstract}

KEYWORDS: Arts; Photography - Art Education - Photography Education - CAp-UERJ.

\footnotetext{
${ }^{1}$ Pesquisador e professor adjunto de fotografia do Instituto de Aplicação Fernando Rodrigues da Silveira (CApUERJ) e Universidade Candido Mendes; pesquisador visitante, Freie Universität, Berlin; fotógrafo e curador.
} 
"Os analfabetos do futuro não serão apenas aqueles que ignorarem a linguagem escrita, mas também todos os que ignorarem o uso da máquina fotográfica".

LazlóMoholy-Nagy, 1936

\section{INTRODUÇÃO}

Houve um tempo em que fotografar era um ato mecânico, individual e solitário. Buscava-se o melhor ângulo, ajustava-se a câmera, apertava-se o botão e a imagem se fazia na química da película. As fotografias reveladas iam para os álbuns, porta-retratos, paredes e, mesmo esquecidas nos fundos de gavetas e caixas nos armários, lá ainda estão para, quem sabe, algum dia ser resgatadas.

$\mathrm{Na}$ contemporaneidade, a facilidade de manuseio da tecnologia, o imediatismo, o baixo custo e, principalmente, o compartilhamento da imagem da imagem digital vêm contribuindo para a massificação de representações do visível, possibilitando que um número cada vez maior de pessoas e, em especial, os mais jovens fotografem tudo, inclusive a si próprios.

Mais recentemente, com a incorporação da captação e edição de imagem em movimento nos inúmeros dispositivos digitais (câmeras, celulares, webcams, tablets, aparelhos de jogos eletrônicos, entre outros) e sua imediata disponibilidade na rede, o registro em vídeo torna cada vez mais abrangente esse fenômeno que podemos chamar de "permanente midiatização" (AUBERT, HAROCHE, 2011). As biIhões de fotografias e vídeos que circulam virtualmente no ciberespaço, mesmo que efêmeras e fugidias, lá também estão para que possamos instantaneamente resgatálas.

Hoje, no entanto, esse resgate é virtual. Olhamos para aquelas imagens que nos são mostradas nas páginas das redes sociais, nas mensagens eletrônicas e nos e-mails. Num clique do mouse ou no toque do teclado, elas já se foram, dando lugar a outras. Raras são aquelas que salvamos como arquivos e ainda mais raras as que imprimimos. E quando o fazemos, provavelmente têm como destino o fundo da gaveta.

As práticas contemporâneas da fotografia e da imagem, configurando-se como uma linguagem universal dos tempos atuais, apontam cada vez mais para a necessidade de uma educação do olhar e uma nova configuração de alfabetização visual $^{2}$.Se até mesmo crianças de quatro ou cinco anos já se tornaram íntimas dessas práticas - tanto na captação como, principalmente, no compartilhamento da imagem - torna-se imprescindível o ensino regular da fotografia no ambiente escolar.

Nesse sentido, há muitos anos, o CAp-UERJ se destaca como uma instituição onde práticas artísticas em várias de suas manifestações - Artes Visuais, Design, Teatro, Música e, particularmente, Fotografia - são valorizadas e oferecidas como disciplinas curriculares do 10 ano do Ensino Fundamental ao 20 do Ensino Médio. $O$ ensino da Fotografia ocorre no 90 ano do Ensino Fundamental e no 10 ano do Ensino Médio, com 100 minutos de aulas semanais.

Após uma breve reflexão sobre a natureza da imagem digital e seu distanciamento cada vez maior do real, trataremos aqui do ensino da Fotografia e alguns de seus desdobramentos na formação dos jovens.

\footnotetext{
${ }^{2}$ Cf. DONDIS (2002), que considera a alfabetização visual tão importante quanto a alfabetização das letras.
} 


\section{A FOTOGRAFIA E O REAL}

Desde sua a invenção, em 1839, a fotografia foi associada ao registro da verdade: um documento visual que para ser realizado independia do lápis e do pincel utilizados pelas mãos humanas. A fotografia foi a resposta definitiva para a demanda de representações mais precisas e fiéis da realidade, demanda essa que tem suas origens no Renascimento, com o desenvolvimento de diversos meios de melhor apresentar o visível. Havia um anseio pela reprodução da natureza e representação da realidade sem a interferência intrusiva do lápis ou do pincel, um "desejo do real" (BRIND et. al., 2007).

A partir do final do século XIX, às suas características "genéticas" de documento e registro, somaram-se as mais variadas formas de expressão artística eternizadas nos trabalhos dos inúmeros fotógrafos que desenvolveram linguagens próprias e duradouras. A fotografia alcançava o status de arte, inserindo-se no campo intelectual e na economia. Ela não mais apenas imitava a natureza, mas passava a moldar a própria cultura.

Com a tecnologia digital, hoje a fotografia se desdobra em múltiplas possibilidades. Criou-se um novo "regime de verdade" e um registro do real diferente daquele que se configurava com a fotografia analógica calcada em processos químicos:

"Enquanto na fotografia a luz e os sais de prata asseguram uma continuidade de matéria entre as coisas e as imagens, na fotografia digital, ao contrário, a ligação está rompida. A imagem digital que é registrada e exibida na tela do computador compõe-se inteiramente de símbolos lógicomatemáticos gerados pela linguagem de programação. Bem no momento da captação, ocorre um contato físico entre as coisas e o dispositivo, mas ele não é mais acompanhado, como acontecia com a fotografia analógica, de uma troca energética entre as coisas e as imagens" (ROUILLÉ, 2009, p. 453).

Enquanto a fotografia química captava e fixava as imagens conferindo-lhes qualidades de suporte da memória, a eletrônica somente capta. Estamos diante de uma "miragem digital" controlada por código binário (BRIND et. al., 2007, p. 16). A fixação não mais ocorre, uma vez que as imagens se sustentam apenas virtualmente e se inserem em outra lógica, a da verdade da rede que se contrapõe à verdade do olhar:

"Deixamos o mundo das imagenscoisas para aquele das imagenseventos, regido por outros usos dessas imagens, outros saberes técnicos, outras equações econômicas, outras práticas estéticas, novas velocidades e novas configurações territoriais e materiais [...] Outras verdades, sem o suporte seguro de uma materialidade fixa, verdades movediças e que se constroem passo a passo [...] verdades paradoxais. A verdade como espuma do falso" (ROUILLÉ, 2010, trad. nossa).

Fato é que hoje a tecnologia digital vem possibilitando a universalização da prática fotográfica de forma inusitada. Todos - incluídos aí, principalmente, os jovens - fotografam e realizam vídeos, produzindo cada vez mais imagens com ampla circulação e recepção na internet: "para os jovens, hoje a experiência da fotografia e da imagem está amplamente ligada a seus usos nas redes sociais e ao computador como parte fundamental de suas vidas" (World Photography Organization, 2012, p. 8, trad. nossa). Constata-se, ainda, a banalização - ou, talvez, a padronização - da produção imagética refletida na semelhança dos olhares, como, por 
e-Mosaicos - Revista Multidisciplinar de Ensino, Pesquisa, Extensão e Cultura do Instituto de Aplicação Fernando Rodrigues da Silveira (CAp-UERJ) V. 4 - N. 7 - JUNHO 2015 - ISSN: 2316-9303

exemplo, os retratos nos perfis das redes das (Figura 1). sociais e as próprias fotografias ali posta-

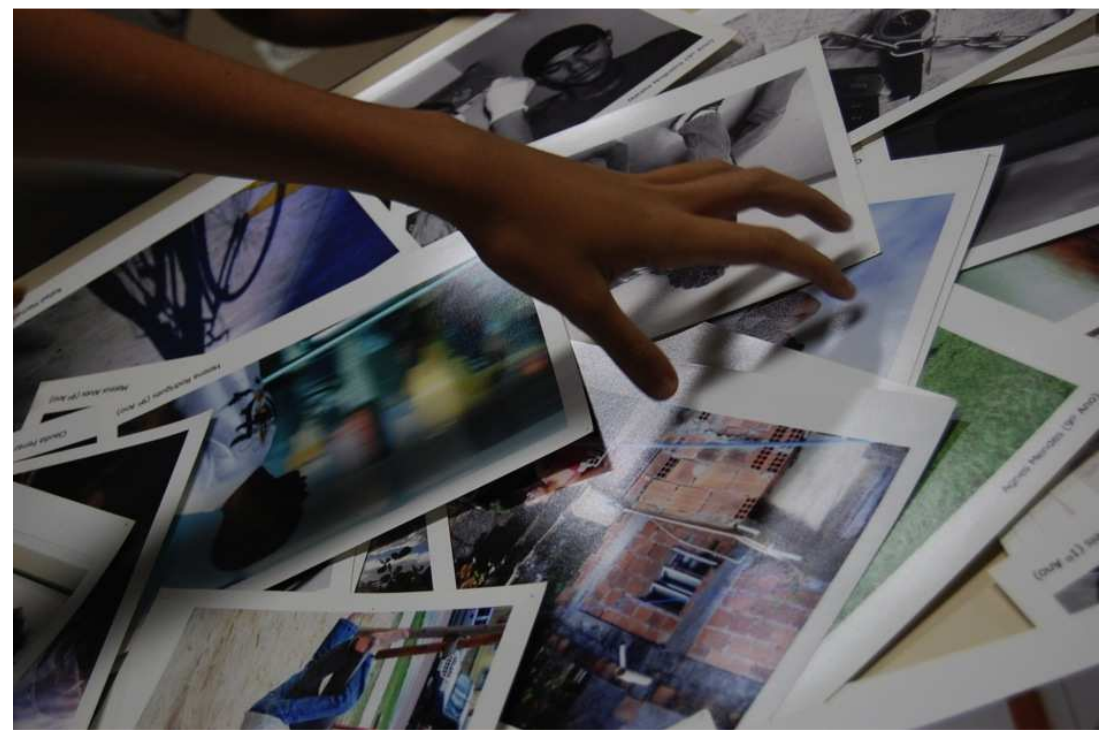

Figura 1: Na sala de aula do CAp-UERJ, acúmulo de imagens e o manuseio de fotos impressas (Foto Andreas Valentin, 2011).

Torna-se necessário, portanto, repensar a fotografia como prática de documentação, de produção artística e de suporte da memória. As imagens digitais "são essencialmente mais provisórias, mutáveis, híbridas e 'em processo' do que as fotografias analógicas" (LISTER, 2004, p. 316, trad. nossa). Vivemos hoje a assim chamada era "pós-fotográfica" (ibid., p. 304) cujas imagens não mais necessariamente refletem ou representam uma visão cartesiana do mundo. Acrescenta-se, ainda que a massificação e a circulação das imagens digitais possibilitam hoje abordagens novas e radicalmente diferentes daquelas vislumbradas na década de 1930 por Walter Benjamin em seu ensaio "A obra de arte na era da reprodutibilidade técnica" (1994, pp. 165-196).

Da mesma forma, abrem-se espaços para uma reflexão sobre as profundas mudanças na prática social e cultural da fotografia, possibilitando que o público e o privado se entrelacem e se confundam, conforme apontado por Fernanda Bruno (2006, p. 140, grifo nosso): "é como se o princípio de visibilidade, que já se sobrepôs ao princípio de realidade no âmbito mais amplo da cena pública, se estendesse às vidas e existências privadas, que passam a requerer a visibilidade como uma espécie de direito ou condição almejada de legitimação e reconhecimento".

Há que se considerar, ainda que o próprio "ato fotográfico" ${ }^{3}$ também se reconfigurou na era digital. Não se aponta

\footnotetext{
${ }^{3}$ Cf. DUBOIS (1993, p. 15): o fazer fotográfico não se resume apenas ao gesto de fotografar, da tomada, mas passa, necessariamente, também pela recepção e contemplação: "a foto não é apenas uma imagem (o produto de uma técnica e de uma ação, o resultado de um fazer e de um saber-fazer, uma representação de papel que se olha simplesmente em sua clausura de objeto finito), é também, em primeiro lugar, um verdadeiro ato icônico, uma imagem se quisermos, mas em trabalho, algo que não se pode conceber fora de suas circunstâncias, fora do jogo que a anima sem comprová-la literalmente: algo que é, portanto, ao mesmo tempo e consubstancialmente, uma imagem-ato $[\ldots]^{\prime \prime}$
} 
e-Mosaicos - Revista Multidisciplinar de Ensino, Pesquisa, Extensão e Cultura do Instituto de Aplicação Fernando Rodrigues da Silveira (CAp-UERJ)

mais uma câmera que antes era uma extensão do olho e, consequentemente, do olhar e que se interpunha entre o fotógrafo e o sujeito. Hoje, estende-se o braço, olha-se para uma tela de cristal líquido e, com a ponta dos dedos, aperta-se, delicadamente, um botão que faz com que o aparelho "processe" uma imagem e ainda emule o som de um obturador de câmera fotográfica. Não é mais apenas o olho que, através do visor/janela da câmera, procura o melhor ângulo e o instante para o disparo. Com as pequenas, leves e totalmente automáticas câmeras digitais é possível até fotografar sem olhar para a tela, produzindo-se, dessa forma, autorretratos, retratos de grupos e imagens mostrando ângulos inusitados. Se, por um lado, a câmera digital possibilita a liberdade do olhar e da experimentação, por outro aponta para um cada vez maior desconhecimento do processo fotográfico. A "caixa preta" e as "imagens técnicas" detalhadas por Vilém Flusser (2002) há mais de trinta anos tornaram-se, novamente, intransponíveis e indecifráveis. Urge, portanto, abrilas e (re)compreendê-las (Figura 2).

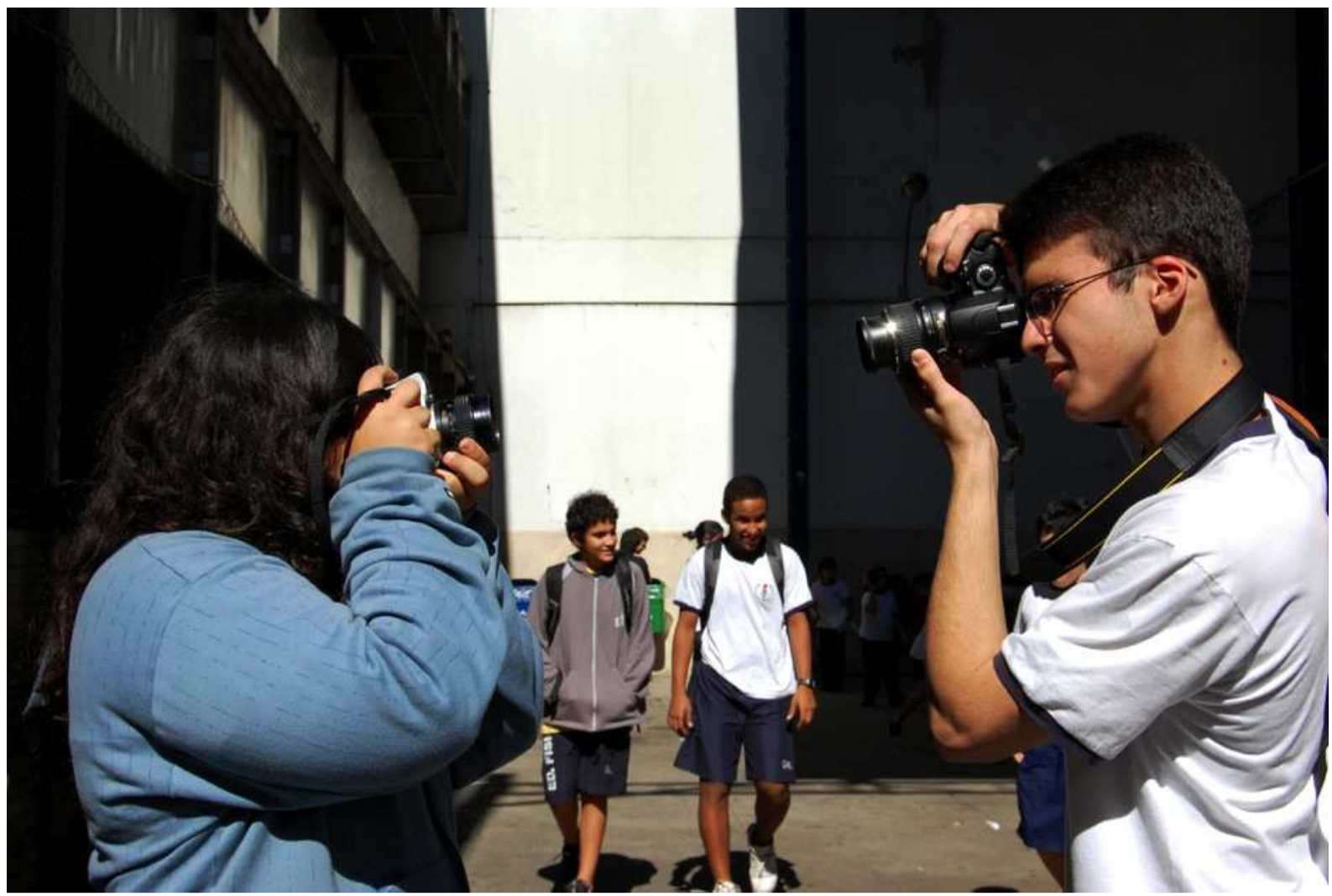

Figura 2: A aluna Alessandra Migueis fotografa no CAp-UERJ com uma câmera analógica, enquanto que o aluno Luís Claudio Dias utiliza equipamento digital (foto Andreas Valentin, 2009). 


\section{ENSINO DA FOTOGRAFIA NOCAP-UERJ: ABRINDO AS CAIXAS PRETAS E OS OLHARES DOS JOVENS.}

A Fotografia é lecionada no CApUERJ desde 1979. Para o 90 ano do Ensino Fundamental, ela é concomitante ao Design. As turmas são divididas em dois grupos de aproximadamente quinze alunos: enquanto um assiste aula de Fotografia, o outro está em Design. Todas as disciplinas de artes - exceto Teatro - são ministradas no subsolo do prédio da Instituição, em salas adequadas para essas práticas. Há dois grandes espaços para Artes Plásticas, com mesas que possibilitam diferentes configurações; duas salas de Música, com instrumentos e equipamentos; uma ampla sala para Design; e a sala/laboratório de Fotografia.

Até 2008, priorizava-se o ensino da fotografia analógica. Havia algumas câmeras, bem como materiais, equipamentos e água corrente para processar filmes e papeis em preto e branco. Naquele ano, tomou-se a difícil decisão de abandonar parcialmente os processos analógicos, dada a dificuldade e o alto custo dos insumos. Foram, então, adquiridas duas câmeras digitais, flashes, uma TV de plasma e, alguns anos depois, através de financiamento da FAPERJ, computadores Mac, um projetor de alta definição e uma impressora.

A fotografia analógica e, em especial, as câmeras que utilizam filmes, são, no entanto, ainda fundamentais para a compreensão de todo o processo e partes importantes na nossa metodologia de ensino. Nesse sentido, realizamos uma campanha de doação de câmeras "antigas" através da qual recebemos algumas de qualidade profissional e em ótimo estado. Elas são utilizadas em vários momentos. No início do curso, para se entender a lógica da "caixa preta", a formação da imagem na câmera e sua semelhança com o olho, o tempo da fotografia e outros aspectos. Já no final, os alunos trazem filmes em cores e, após algumas aulas de aprendizado sobre o manuseio técnico dos equipamentos divididos em grupos, realizam fotografias nos espaços da Instituição.

Essa prática tem sido bem sucedida, principalmente por permitir que os alunos exercitem um dos objetivos principais da disciplina: pensar antes de apertar o botão ${ }^{4}$. A utilização das máquinas analógicas impõe olhar através do visor e não para uma tela; fazer o foco com as lentes de extrema precisão; medir a exposição; realizar os ajustes de velocidade/abertura e somente então acionar o disparador. Trata-se de um processo lento que se contrapõe à rapidez e ao automatismo da fotografia digital. Os alunos são obrigados a desacelerar e refletir sobre cada fotografia que produzem. Eles próprios comentaram sobre os aspectos positivos desse exercício:

"Com a câmera analógica, você tem que ter mais cuidado com a composição, porque não pode apagar/deletar a foto depois" (C. Q., $9^{\circ}$ ano).

"Com as câmera antigas, há uma dificuldade maior em utilizar o equipamento, exigindo mais aptidão. Isso muda muito a forma de ver o mundo através da câmera. Nas câmeras atuais está tudo pra mais fácil; isso faz a pessoa não pensar. E eu corrigi algumas coisas que eu já sabia fazer" (J. P., $9^{\circ}$ ano).

"Só de ouvir o barulhinho, parece que você sente melhor o que a-

\footnotetext{
${ }^{4}$ A grande maioria das fotografias digitais são realizadas de forma automática, não requerendo esforço intelectual de quem fotografa. É interessante lembrar da semelhança com o processo inventado por George Eastman no final do século XIX: o filme de rolo $35 \mathrm{~mm}$ e as câmeras "Brownie" que foram responsáveis pela primeira massificação da prática fotográfica. Seu slogan de propaganda dizia: "Você aperta o botão e nós fazemos o resto".
} 
contece. Na outra, é a câmera que tira a foto, não você" (J. P. M., 90 ano).

"Aprende-se muito mais sobre fotografia, porque tem que ajustar com as suas mãos e não apenas apertar botões" (L. S., 90 ano). ${ }^{5}$

Outro aspecto importante é o tempo de espera da fotografia. No processo digital, a imagem se faz em frações de segundo e, imediatamente, torna-se visível. No analógico, também é registrada naquelas mesmas frações de segundo, porém quem a realiza só a vê horas ou dias depois. A aluna Luiza Cavalcanti comentou que "ficava ansiosa" por não saber como as fotos ficariam. Essa ansiedade relaciona-se com o próprio fascínio da imagem técnica que, diante do imediatismo parece, também, estar se tornando cada vez menos presente.

Partindo do pressuposto de que hoje quase todos têm câmeras e/ou dispositivos eletrônicos que possibilitam captura e processamento de imagens ${ }^{6}$, o programa de ensino da Fotografia inicia-se com o exercício "Meu Mundo" - dez fotografias que retratam o mundo dos alunos e cuja única regra é que devem ser realizadas por eles próprios. Ao longo de um mês, essas imagens são exibidas, comentadas e criticadas na sala de aula. As fotografias mais recorrentes mostram a escola, a casa (em especial, o quarto), a rua, os parentes, os amigos e os animais de estimação. Alguns olhares mais apurados, geralmente dos alunos mais velhos, buscam imagens

\footnotetext{
${ }^{5}$ Os depoimentos foram coletados ao longo de três anos em sessões de avaliação da disciplina, realizadas no final do ano letivo.

${ }^{6}$ No início do ano letivo, realizo uma enquete informal com os alunos para conhecer seu acesso ao uso de câmeras, celulares e/ou outros dispositivos. Nota-se um aumento significativo de alunos que têm equipamentos próprios - alguns, inclusive, de qualidade semiprofissional - ou que podem utilizar os de seus familiares.
}

menos explícitas e documentais. Se por um lado, em algumas as sociabilidades desses jovens são claras e nitidamente identificáveis - como, por exemplo, os colegas da escola na sala de aula ou na hora do recreio, os pais na sala ou na cozinha em outras, se revelam de forma mais sutil e necessitam de uma explicação verbal que complemente a imagem: "meu pai no tanque, porque eu moro com ele e é ele quem lava minha roupa" ou "eu na cozinha, porque lá em casa eu faço um monte de coisas". São recorrentes comentários como "ele não tem família", quando um aluno mostrou fotos de lugares sem pessoas.

Antes mesmo de serem apresentadas, muitas dessas imagens vão para a internet, ilustrando aspáginasdos alunos no Facebook. Configura-se ali uma espécie de "mitologia pessoal", construída "a partir de pedaços e fragmentos de informações extraídos do fluxo midiático", possibilitando a compreensão de uma vida cotidiana (JENKINS, 2009, p. 30). Esse fluxo se manifesta pela troca e compartilhamento de imagens - tanto estáticas como em movimento $^{7}$ e se caracteriza, também, pelo acúmulo e pela grande quantidade de informações.

Ao longo do ano letivo são realizados outros exercícios práticos, como "Retrato e Autorretrato" (90 ano), fotografia de estúdio (1o ano), narrativas fotográficas (9o ano), entre outros. Todos os trabalhos são exibidos e amplamente comentados na sala de aula. Há, ainda, aulas práticas e teóricas que incluem: o funcionamento das câmeras e instruções para melhorar a qualidade técnica das fotogra-

\footnotetext{
${ }^{7}$ Ressalta-se que a tecnologia digital eliminou definitivamente as fronteiras entre a imagem estática (fotográfica) e em movimento (cinema e vídeo). Aqui, o conceito de "convergência" (cf. JENKINS, 2009, p. 44) é, talvez, mais evidente: "a convergência envolve uma transformação tanto na forma de produzir quanto na forma de consumir os meios de comunicação".
} 
fias; história da fotografia; composição e aspectos estéticos; leitura de imagens a partir de livros de fotografias; visitas a exposições; exibição de filmes. Recursos didáticos incluem os equipamentos audiovisuais e a utilização da internet (Figura 3).

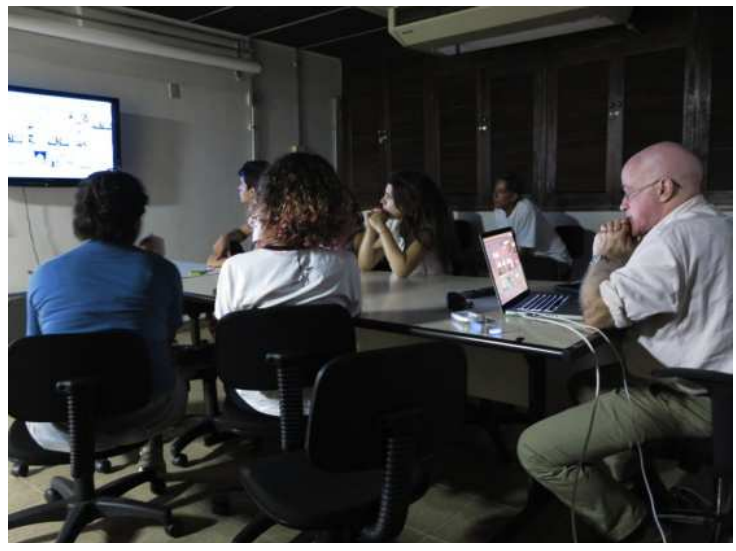

Figura 3: Alunos e professor na sala de aula; ao fundo, um aluno licenciando do Instituto de Artes da UER] (foto Hevellin Costa, 2012).

Num cotidiano onde as relações sociais e a fruição estética parecem se diluir no virtual, no programa da disciplina procura-se sempre ressaltar a diferença entre as imagens "aleatórias" - como eles próprios denominam fotografias feitas de qualquer maneira e enviadas para as redes sociais - e aquelas que realmente possuem significados. Na verdade, mais do que entender como uma foto foi feita, é preciso saber por que ela foi feita.

Outra questão crucial relaciona-se à ética na fotografia. Hoje, num clique do mouse, é possível copiar uma imagem do computador, dela se apropriar e compartiIhar na rede. Desde o início, é enfatizada a importância e o cuidado com autoria, direitos de imagem de terceiros, originalidade e privacidade. Houve um caso onde uma aluna copiou da internet uma imagem de uma colega e a trouxe para a sala de aula como sendo sua. Ela estava convicta de que não havia feito nada de errado: "Mas, qual o problema, professor? Todo mundo faz isso!" Foi preciso explicar para ela e para seus colegas as diferenças entre "compartilhar" e "copiar".

Depoimentos de algumas alunas do 90 ano resumem algo do que aprenderam, reforçando alguns dos objetivos da disciplina:

"Tenho uma nova perspectiva na fotografia. Não só por conseguir tirar fotos melhores, mas também porque me ajudou a criar uma nova percepção do mundo" (L. P. W.).

"Ajudou-me a conhecer as pessoas através da fotografia" (L. M. S.).

"... uma pausa entre as aulas mais 'pesadas' que a gente tem" (N. S.).

Por outro lado, em 2013, pela primeira vez, as aulas foram abertamente criticadas por um aluno. Ele não gosta de fotografar, considera inútil a Fotografia e, portanto, seu aprendizado na escola. Ele faz os trabalhos "porque é obrigado; se não fizer, levo zero".

\section{RIOJOVEM: O ENSINO dA Fotografia PARA ALÉM DA SALA DE AULA}

Um importante desdobramento das práticas na sala de aula é o projeto "RioJovem". Desde 2009, os alunos percorrem o Rio de Janeiro apontando suas câmeras para um universo que lhes é íntimo e familiar: os jovens de sua cidade. A ideia surgiu a partir de uma visita dos alunos à exposição de fotografias "Ser jovem na França", exibida naquele ano na Caixa Cultural. Duas alunas sugeriram: "Por que não fazemos o mesmo aqui no Rio de Janeiro?". Daí veio o nome (também sugestão delas) e a tarefa que foi passada para as turmas: realizar fotografias retratando 
jovens no Rio de Janeiro. Eles foram divididos em equipes e algumas poucas regras foram estabelecidas: as fotografias deveriam ser inéditas e realizadas na cidade ou no estado do Rio de Janeiro, pelos próprios alunos e retratando jovens entre idade aproximada de 12 a 25 anos; não deveriam ter qualquer tipo de manipulação, excetuando-se a possibilidade de realizá-las em preto e branco ${ }^{8}$.

Três semanas depois, as imagens foram apresentadas e surpreenderam a todos, não só pela qualidade, mas, principalmente, pela variedade de temáticas abordadas. Essa produção foi mostrada para nossa colega da equipe de artes do CAp-UERJ, professora Claudia Saldanha, à época diretora da Escola de Artes Visuais do Parque Lage, tradicional espaço de ensino e pesquisa das artes no Rio de Janeiro ${ }^{9}$. Como todos nós, ela também se entusiasmou com o que viu e propôs uma exposição no Parque Lage. $E$, assim, uma seleção de 150 imagens impressas em papel fotográfico foi mostrada de 7 a 15 de novembro de 2009.

Essa parceria foi determinante para que o projeto pudesse se abrir para além dos muros da escola, possibilitando uma ampla visibilidade aos trabalhos realizados pelos alunos e, dessa forma, estimulandoos a um maior empenho e dedicação. Exibidas em uma galeria de arte, as fotografias passaram a ter, ainda, um valor simbólico como obras de arte.

Todo o processo foi realizado pelos alunos. As turmas do 90 ano (aproximadamente 120) foram divididas em grupos e incentivadas a pensar e produzir suas fotos coletivamente, estimulando o trabaIho em equipe. Em alguns encontros, eles próprios selecionaram as imagens que

\footnotetext{
${ }^{8}$ Desde 2012, foi incorporada também a captura e processamento de imagens através de aplicativos para celulares, como o Instagram.

http://www.eavparquelage.rj.gov.br/ a EAV:
}

gostariam que fossem submetidas à seleção final. A turma do 10 ano (aproximadamente 20), além de realizar também suas fotografias, participou ativamente da produção da exposição cuidando de algumas de suas etapas, entre elas, o tratamento das imagens e sua adequação para o formato final, divulgação, montagem e desmontagem.

Um grupo de quatro alunos do 10 ano examinou detalhadamente cerca de 500 fotografias selecionadas na última triagem, para escolher as 150 que iriam compor a exposição no Parque Lage. Nesse processo, as imagens foram agrupadas por assuntos e outras afinidades- estéticas, visuais, sociais - para a montagem nas paredes da galeria. Surgiram, também, algumas questões que trespassam a própria produção imagética contemporânea, como, por exemplo, a já mencionada autoria - descobriu-se que algumas fotografias haviam sido copiadas da internet e qualidade técnica - uma fotografia expressiva, porém produzida nas baixas resoluções de aparelhos celulares ou tremida, deveria ou não ser incluída?

As fotografias realizadas em 2009 para o projeto "RioJovem" - tanto as selecionadas para exibição pública como, principalmente, o material bruto - começaram a formar um corpus imagético que pode ser entendido como representativo das práticas, hábitos e sociabilidades de jovens no Rio de Janeiro. Deve-se considerar que essas imagens, por terem sido produzidas e selecionadas por seus semelhantes, configuram sentidos e valores que ultrapassam sua superfície, pois retratam e documentam não apenas indivíduos, mas um grupo social. E ainda, conforme reforça SIMMEL (1971, p. 133, trad. nossa): "porquanto que sociabilidade é uma abstração da associação - uma abstração do caráter de arte ou brincadeira - ela requer uma tipo de interação que seja a mais pura, mais transparente, mais envolvente: aquela que se dá entre semelhantes". 
e-Mosaicos - Revista Multidisciplinar de Ensino, Pesquisa, Extensão e Cultura do Instituto de Aplicação Fernando Rodrigues da Silveira (CAp-UERJ)

Além dos benefícios desse aprendizado, os alunos construíram verdades fotográficas (mesmo que movediças, conforme apontado anteriormente) com seus olhares e suas imagens documentais, expressivas e artísticas, contemplando uma etnografia de sua cultura e suas sociabilidades. O próprio fazer dessas imagens, sua circulação na rede e sua exibição em suporte físico (o papel fotográfico) abrangeram algumas das inúmeras possibilidades da fotografia na contemporaneidade.
Dois anos depois, foi realizada a segunda exposição, contemplando fotografias dos alunos de 2010 e 2011. Inscrito no Departamento de Extensão da Subreitoria de Extensão e Cultura da UERJ, o projeto ganhou mais visibilidade e consistência levando a produção fotográfica e o ensino da Fotografia para além dos muros da escola. Essa exposição foi depois exibida na UERJ (Figura 4).

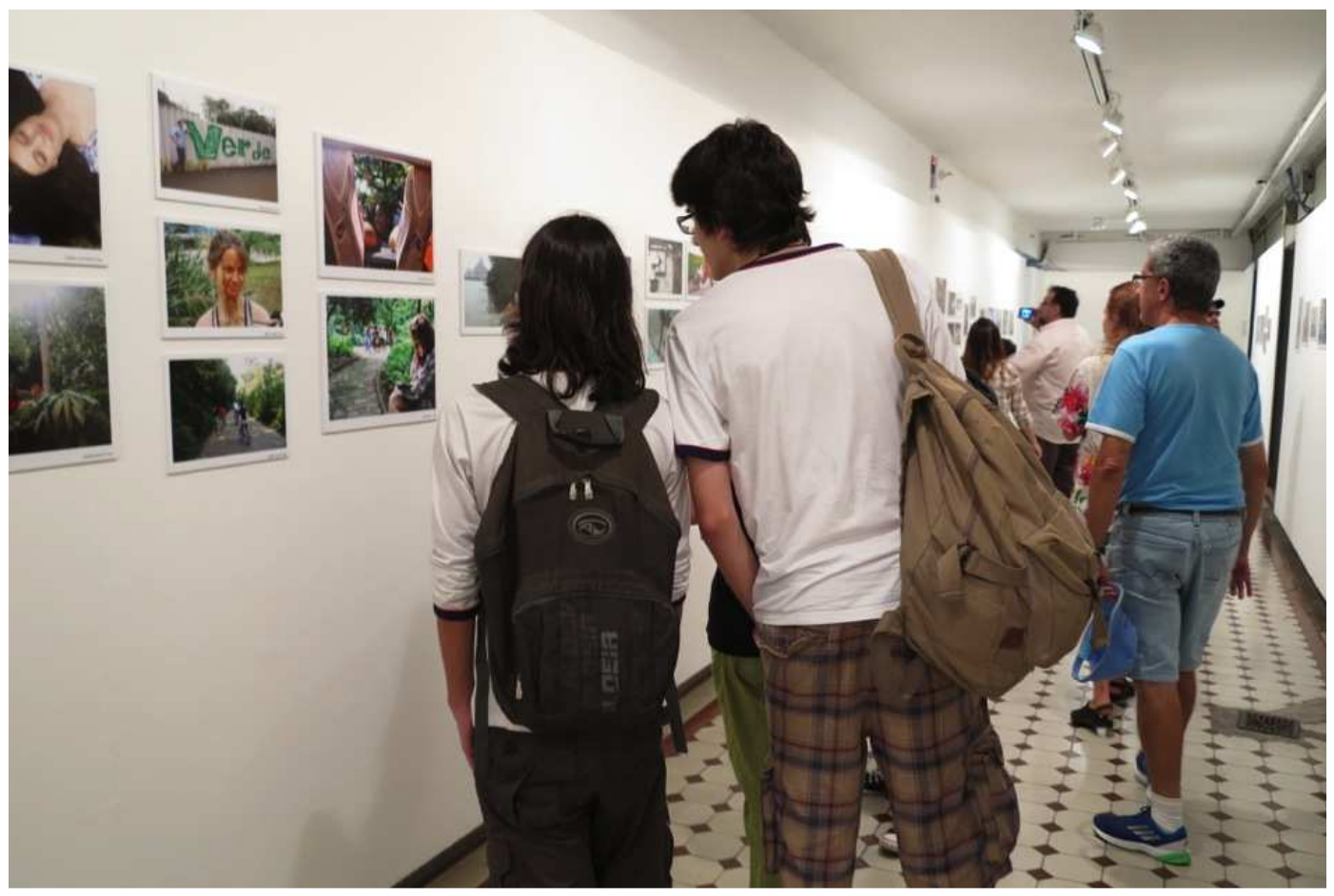

Figura 4: Alunos, colegas e familiares visitam a exposição "RioJovem" na Escola de Artes Visuais do Parque Lage (foto Andreas Valentin, 2013). 
Em 2012, dois importantes parceiros se integraram ao projeto. Inicialmente, o Canal Futura, que através de sua equipe de videografismo apoiou a ideia de produzir com os alunos narrativas fotográficas curtas para serem exibidas como interprogramas na grade da emissora. Após um longo processo de criação e execução pelos alunos e finalização pelos artistas do Futura, duas dessas peças estão hoje sendo exibidas.Nesse mesmo ano, o projeto foi contemplado no edital da FAPERJ "Produção e divulgação das artes no Rio de Janeiro", possibilitando a aquisição de equipamentos, aporte de verba para a realização da exposição de fotos em 2013 com melhor acabamento e, principalmente, a concepção, elaboração e implementação de um site interativo: www.riojovem.com.br. Fundamentais para o processo de aprendizado, ações como as exposições de fotografias são, no entanto, efêmeras. É através das plataformas virtuais que se torna possível disponibilizar e eternizar essa informação para o grande público.

Por isso, o site foi pensado como um blog para atender a duas demandas: exibir essa produção fotográfica e possibilitar a interatividade, através de posts submetidos pelos professores e bolsistas do projeto, bem como dos próprios alunos. Suas quatro abas atendem a essas necessidades. Na primeira, "O Projeto", RioJovem é explicitado de forma resumida. Na seguinte, "Expo", são exibidas as fotografias das exposições realizadas em 2009, 2011 e 2013. "Alto Falante" é um espaço para informações sobre fotografia, imagem e suas inúmeras práticas. Já "Portal" permite que os alunos façam uploads de seus trabalhos regulares da disciplina além de outras produções; possibilita, também, o envio de comentários. O site está totalmente integrado ao Facebook e à página do projeto, ativa desde 2012.

\section{CONCLUSÃo}

Após mais de cinco anos praticando a Fotografia com alunos do CAp-UERJ, é possível mapear alguns resultados e também evoluções nesse processo. Inicialmente, há de se ressaltar a importância desse aprendizado na formação dos jovens. Mesmo que, talvez, muitos deles não se conscientizem de imediato desse fato, é certo que mais adiante essa "alfabetização do olhar" terá se cristalizado de formas diversas.

$\mathrm{Na}$ contemporaneidade, com o acúmulo de informações, nossa atenção e, principalmente, a dos jovens torna-se cada vez mais curta e mais dispersa. Vivemos na era da "cultura das telas" (BURDICK et. al., 2012, p. 11), constantemente bombardeados por imagens, sons e outros estímulos digitais. É preciso, primeiro,entender e, em seguida, incorporar essas práticas. Uma vez que "novas formas de conhecimento são propiciadas nos ambientes digitais conectados em rede" (ibid., p. 7), deve-se fazer amplo uso dessas tecnologias na educação, em especial, naquela que lida com conteúdos audiovisuais.

É nessa direção que o ensino da Fotografia no CAp-UERJ vem apontando, buscando sempre adequar seu currículo e suas ações às necessidades e anseios da sociedade e, principalmente, dos próprios alunos.

"Descobri um fotógrafo dentro de mim"

L. G., aluno do 90 ano, $13 / 6 / 2013$

\section{REFERÊNCIAS BIBLIOGRÁFICAS}

AUBERT, Nicole; HAROCHE, Claudine, Lestyrannies de lavisibilité. Paris: Éditionsérès, 2011.

AUMONT, JACQUES, $A$ imagem. Campinas: Papirus, 1995. 
BARTHES, ROLAND, $A$ câmara clara. Rio de Janeiro: Nova Fronteira, 1984.

BAZIN, André, "A ontologia da imagem fotográfica". In XAVIER, Ismail (org.), $A$ experiência do cinema. Rio de Janeiro: Edições Graal, 2003.

BENJAMIN, Walter, Magia e técnica, arte e política: ensaios sobre literatura e história da cultura. São Paulo: Brasiliense, 1994 (Obras escolhidas; v. 1).

BRUNO, Fernanda, "Quem está olhando? Variações do público e do privado em weblogs, fotologs e reality shows". In FATORELLI, Antonio e BRUNO, Fernanda (org.), Limiares da imagem: tecnologia e estética na cultura contemporânea. Rio de Janeiro: Mauad Editora, 2006.

BOURDIEU, Pierre, Photography: a middlebrow art. Stanford: Stanford University Press, 1990.

BURDICK, Anne; DRUCKER, Johanna; LUNENFELD, Peter et. al, Digital Humanities. Cambridge: MIT Press, 2012.

DONDIS, Donis A, Sintaxe da linguagem visual. São Paulo: Martins Fontes, 2002.

DUBOIS, Philippe, $O$ ato fotográfico. Campinas: Papirus, 1993.

Flusser, Vilém, Filosofia da caixa preta. Rio de Janeiro: RelumeDumará, 2002.

JENKINS, Henry, Cultura da convergência. São Paulo: Aleph, 2009.

KOSSOY, Boris, Os tempos da fotografia. São Paulo: Ateliê Editorial, 2007.

LISTER, Martin, "Photography in the age of electronic imaging". In: WELLS, Liz (Org.) Photography: a critical introduction. London: Routledge, 2004.
PRICE, Derrick; Wells, Liz, "Thinking about photography". In: WELLS, Liz (Org.) Photography: a critical introduction. London: Routledge, 2004a.

ROSENBLUM, Naomi, $A$ world history of photography. New York: Abbeville Press, 1997.

ROUILLÉ, André, $A$ fotografia: entre documento $e$ arte contemporânea. São Paulo: Ed. SENAC, 2009. "Lesvérités relatives de laphotographie." Disponível em www.paris-art.com/art-culture-France/Les véritésrelatives de laphotographie/311.html. Acesso em $21 / 4 / 2010$

SIMMEL, Georg, On individuality and social forms. Selected writings, edited and with an introduction by Donald $N$. Levine. Chicago: The University of Chicago Press, 1971.

SONTAG, Susan, Ensaios sobre fotografia. Rio de Janeiro: Editora Arbor, 1981.

SUTTON, Damian; BRIND, Susan; McKENZIE, Ray, The state of the real: aesthetics in the digital age. London: I. B. Tauris \& Co., 2007.

WELLS, Liz (Org.) Photography: a critical introduction. London: Routledge, 2004.

WORLD PHOTOGRAPHY ORGANIZATION, "Notes for Photography Educators" from Photography Education Symposium. London: 2012
Recebido em: 02/06/2015 Aceito em: 30/06/2015 